\title{
An Overview of the Synthesis and Synthetic Mechanism of Poly (Lactic acid)
}

Cheolho Lee and Sungyeap Hong*

Chemical and Biological Engineering Department, Seokyeong University, Korea

\begin{abstract}
Poly(lactic acid) is the biodegradable aliphatic polyester produced in small quantity and in large quantities industrially and used very variously. Because of its good mechanical property and reconcilability with environment, it is one of the polymers most appropriate to replace non-biodegradable synthetic polymers based on crude oil. PLA can be made from lactic acid with different polymerizations such as polycondensation, ring-opening polymerization, and direct polymerizations by azeotropic dehydration or the enzymatic polymerization. The direct polymerization and the ring-opening polymerization are the most used techniques. This paper reviewed methods of making PLA such as oligomer polycondensation or ring-opening polymerization and mainly mechanism of ring-opening polymerization with 4 areas: metal catalyst, organic catalyst, cationic catalyst and stereo-controlled polymerization.
\end{abstract}

Keywords: Poly (lactic acid); Synthesis; Mechanism; Polycondensation; Ring opening polymerization

\section{Introduction}

Plastics based on synthetic polymers using crude oil as a raw material are widely used in various areas such as packing, electrical equipment, construction materials, and farming. As these plastics based on synthetic polymers are not biodegradable, they severely cause environmental problems. Therefore, high expectations are being placed on the biodegradable polymers gained from the renewable raw materials. Biodegradable polymers gained from the renewable materials can be classified into 3 categories according to their raw material and synthetic method: the first, they are polymers extracted from the agricultural products such as cellulose; the second, polymers made by microorganism such as poly(hydroxyalkanoate); and the third, synthetic polymers using monosaccharide that can be obtained from agricultural products such as PLA [1,2]. Of them, there are high interests in eco-friendly and biodegradable polyesters such as PLA for the medical and biodegradable uses [3-8].

Lactic acid (2-hydroxypropionic acid) is the chiral molecule that L-lactic acid and D-lactic acid exist as two enantiomers [9,10]. Lactic acid is one of the monomers that can be well transformed chemically as it has carboxylic acid and hydroxyl group [11].

\section{Poly(Lactic acid)}

Poly(lactic acid) (PLA) is a biodegradable polymer, so it is used very variously, from for food packing to for biomedicine. Because of its mechanical property, transparency and eco-friendly nature, it is highlighted as the best material to replace non-degradable polymers [12]. As the lactic acid has two stereo-isomers, L-lactic acid and D-lactic acid, its polymer product can be synthesized in many forms such as poly(L-lactic acid) PLLA, poly(D-lactic acid PDLA or racemic products. The PLLA synthesis process that used a direct polymer condensation reaction makes high purity polymer products $[13,14]$. This L-isomer is the biological metabolite, and most of the PLAs made from the renewable raw materials are L-isomer.

PLA compounds melt well by dioxane or chloroform generally. In the solvents such as toluene, acetone and THF, it melts in small quantity at low temperature, but melts well at boiling temperature. Polymers based on lactic acid do not melt in methanol, ethanol, water, hexane and heptane. PLLA crystals do not melt in ethyl acetate, THF, and acetone $[15,16]$. Some of PLA's properties are cited in Table 1.

\section{The Synthesis of Poly(Lactic Acid)}

As PLA is a compound that has the highest possibility to replace synthetic non-biodegradable polymers without biodegradability, there have been many studies of the synthesis to improve its material property or optical property $[15,17,18]$

PLA can be made through a polymerization process from the lactic acid by polycondensation or ring opening polymerization, or can be made by direct methods such as azeotropic dehydration or enzymatic polymerization $[9,12]$. The direct polymerization and ring opening polymerization are the most generally used methods (Figure 1).

\section{Oligomer Polycondensation}

As the lactic acid has both $-\mathrm{OH}$ and $-\mathrm{CO}_{2} \mathrm{H}$ groups, it can do condensation reaction by itself. Even though oligomer polycondensation is the cheapest reaction process, the process can include solutions such as water and organic solvents. To remove water produced in this condensation process, solvent and catalyst are used in the high temperature and high pressure environments. It is very hard to make PLA with high molecular weight that does not include solvents [17]. This produced polymer is a matter with low or medium molecular weight, which is used by itself or used by combining with epoxide or isocyanates to make various molecular weights [10].

The polycondensation makes oligomer with tens of thousands of molecular weights. In general, the direct polycondensation is composed of 3 steps: removal of water, polycondensation of oligomer, and melt condensation that makes PLA with high molecular weight. Direct polycondensation of lactic acid is the competitive reaction that forming and decomposition processes of lactide simultaneously, so it is not used for the large producing reaction [19-22]. In early

*Corresponding author: Sungyeap Hong, Professor, Chemical and Biological Engineering Department, Seokyeong University, 124 Seokyeong-Ro, Sungbuk-Ku, Seoul 136-704, Korea, Tel : +82-10-8970-7186; E-mail: sungyeap@skuniv.ac.kr

Received December 01, 2014; Accepted December 25, 2014; Published December 29, 2014

Citation: Lee C, Hong S (2014) An Overview of the Synthesis and Synthetic Mechanism of Poly (Lactic acid). Mod Chem appl 2: 144. doi: 10.4172/2329-6798.1000144

Copyright: @ 2014 Lee C, et al. This is an open-access article distributed under the terms of the Creative Commons Attribution License, which permits unrestricted use, distribution, and reproduction in any medium, provided the original author and source are credited. 


\begin{tabular}{|c|c|c|c|}
\hline $\begin{array}{c}\text { Lactic acid } \\
\text { polymers }\end{array}$ & $\begin{array}{c}\text { Glass Transition } \\
\text { Temperature } \mathbf{T}_{\mathbf{g}}\left({ }^{\circ} \mathbf{C}\right)\end{array}$ & $\begin{array}{c}\text { Melting Temperature } \\
\mathbf{T}_{\mathbf{m}}\left({ }^{\circ} \mathbf{C}\right)\end{array}$ & $\begin{array}{c}\text { Density } \\
\left(\mathbf{g} / \mathbf{c m}^{\mathbf{3}} \mathbf{)}\right.\end{array}$ \\
\hline PLLA & $55-80$ & $173-178$ & 1.290 \\
\hline PDLLA & $43-53$ & $120-170$ & 1.25 \\
\hline PDLA & $40-50$ & $120-150$ & 1.248 \\
\hline
\end{tabular}

Table 1: Lactic acid polymers properties $[15,16]$

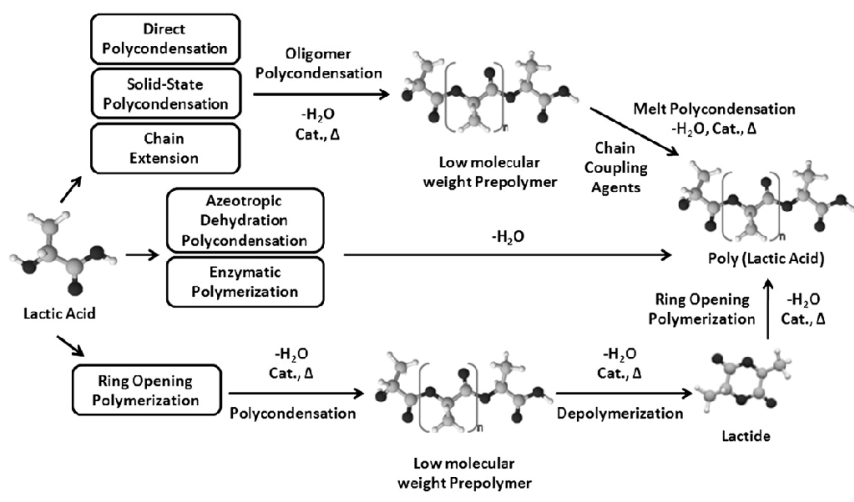

Figure 1: The Synthetic Routes for Poly(Lactic Acid) [9]

days, this direct polycondensation was thought as the reaction that produces useless polymers with low molecular weight, but now this condensation reaction can produce polymers with considerably high molecular weight [23-25].

\section{Melt Polycondensation}

Melt polycondensation can be carried out without any organic solvent, but its reaction temperature should be above Tm of its polymer [26]. This method is simple so the costs of synthesis can be remarkably reduced, but sensitivity of its reaction condition is a big problem to be solved [27]. Water produced through this process becomes a cause to decompose PLA with high molecular weight at high reaction temperature. Chain-extension reaction is an effective method that makes PLA with high molecular weight by polycondensation [28]. In this method, the intermediate with low molecular weight is used as the chain coupling polymer to connect molecules with low molecular weight with polymers with high molecular weight.

\section{Solution Polycondensation}

In this polycondensation reaction, organic solvents are used to melt PLA without hindrances to reaction, and the reflux method is used to remove water. Many methods that make PLA with average molecular weight above 20,000 with this method were reported [29,30].

\section{Ring-Opening Polymerization}

Ring-Opening Polymerization (ROP) is the most general method that can obtain PLA with high molecular weight. Purity of the lactide monomer combined 2 lactic acids is important to this reaction. This reaction was conducted by the ring-opening reaction of lactide in the condition with catalyst, and was conducted by 3 stages of polycondensation, de-polycondensation and ring-opening polymerization [31]. Many kinds of initiators are known, and stannous octoate of them is used a lot, as it provides high reaction velocity, high rate of transformation, high molecular weight, and relatively mild reaction condition [19].

Ring-opening polymerization of lactide intermediate by catalyst can synthesize PLA that has adjustable molecular weight $[10,32]$.
Many nontoxic catalysts derived from magnesium, calcium, zinc, alkali metals, and aluminum have been developed for the ROP of lactides to solve pollution problems caused by heavy metal catalysts [33-38].

\section{Enzymatic Polymerization}

Enzymatic polymerization is one of the best alternative methods that can synthesize PLA that has the better physical and chemical properties, and is the eco-friendly method that can react in the mild condition. This method can make polymerization process properly adjusted [39]. There are still many problems to be solved both in terms of research and production, but the LA-polymerase working in place of metal catalyst can perform biosynthesis of PLA.

\section{The Mechanisms for the Ring Opening Polymerization}

Generally, there are 3 reaction mechanisms in the ring-opening polymerization of lactide: cationic, anionic and coordination mechanisms. Because of the highly reactive anionic reactants that hinder growth of chain, the anionic polymerization becomes a cause of undesirable reactions such as racemization, decomposition reaction and other side reactions. The cationic polymerization can cause undesirable side reactions or racemization because of the nucleophile reaction to the active center. This research developed the ring-opening reaction mechanism in 4 areas: metal catalysts, organic catalysts, cationic catalysts and stereo-controlled polymerization.

\section{Metal Catalysts}

Metal complexes of $\mathrm{Al}, \mathrm{Mg}, \mathrm{Zn}, \mathrm{Ca}, \mathrm{Sn}$ and $\mathrm{Zr}$ are widely used as catalysts for ROP of lactide. Stannous(II) 2-ethylhexanoate ( $\left.\mathrm{Sn}(\mathrm{Oct})_{2}\right)$ is one of the catalysts most widely used as a compound that starts the ring opening polymerization (ROP) of various lactones and lactides [40-42].

In the reaction system with L-lactide and 1,5-dioxepan-2-one (DXO), initial complex of methanol and stannous(II) 2-ethylhexanoate $\mathrm{Sn}(\mathrm{Oct})_{2}$, coordination-insertion mechanism that makes ROP of L-lactide occurred by $\mathrm{Sn}(\mathrm{Oct})_{2}$ is known. Reaction mechanisms with L-lactide or DXO are identical, and this review arranged reaction mechanisms using DXO in Figure 2.

In the initial process, weak polymerization of monomer occurs in complex 3. As a result, the complex has a part of carboxylic acid from process 4 to TS56, and the structure is stabilized through hydrogen bond. After the compound 4 is formed, methoxy group does nucleophilic attack to carbonyl carbon of monomer, and a new $\mathrm{C}-\mathrm{O}$ combination is made between monomer and methoxy group, by going through TS45, a 4-center transition state.

The second example is ROP of L-lactide that uses $\mathrm{ZnL}_{2}(\mathrm{~L}=$ aminophenolate) or $\mathrm{Sn}(\mathrm{Oct})_{2}$ (Oct $=$ bis(2-ethylhexanoate) $)$ as the initiator and propargyl alcohol as the co-initiator [43] (Figure 3).

According to Jędrzkiewicz et al. [43], after Zn complex coordinates a molecule of lactide to the center of metal, a molecule of alcohol combines with phenolate oxygen donor by hydrogen bond in Figure 3. The initial reaction occurs through insertion of alkoxy group with lactide. Catalytically cyclic process that produces PLA continues until lactide is consumed. The next process is the addition reaction of lactide and alcohol with the same molar ratio.

\section{Organic Catalysts}

As there are problems of metal pollution in the reaction by metal catalysts, there have been a lot of efforts to develop biocompatible 


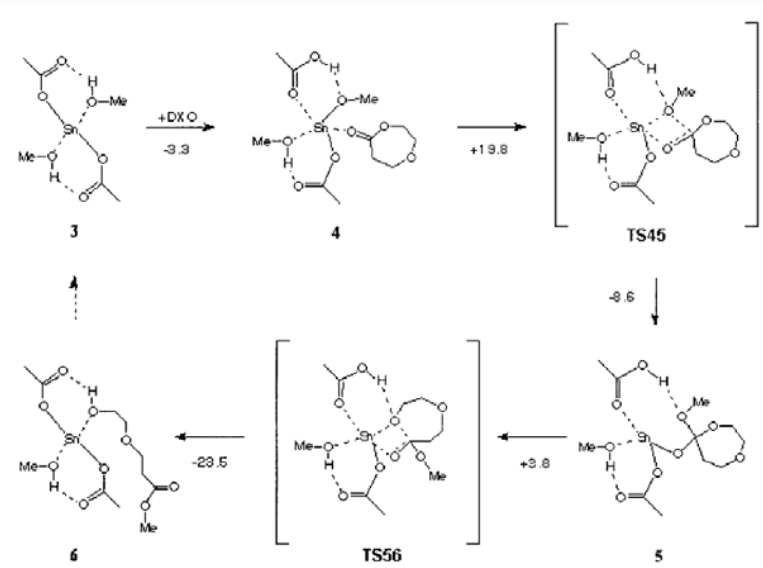

Figure 2: The coordination-insertion mechanism involving the ROP of DXO with $\mathrm{Sn}(\mathrm{Oct}) 2[40]$.

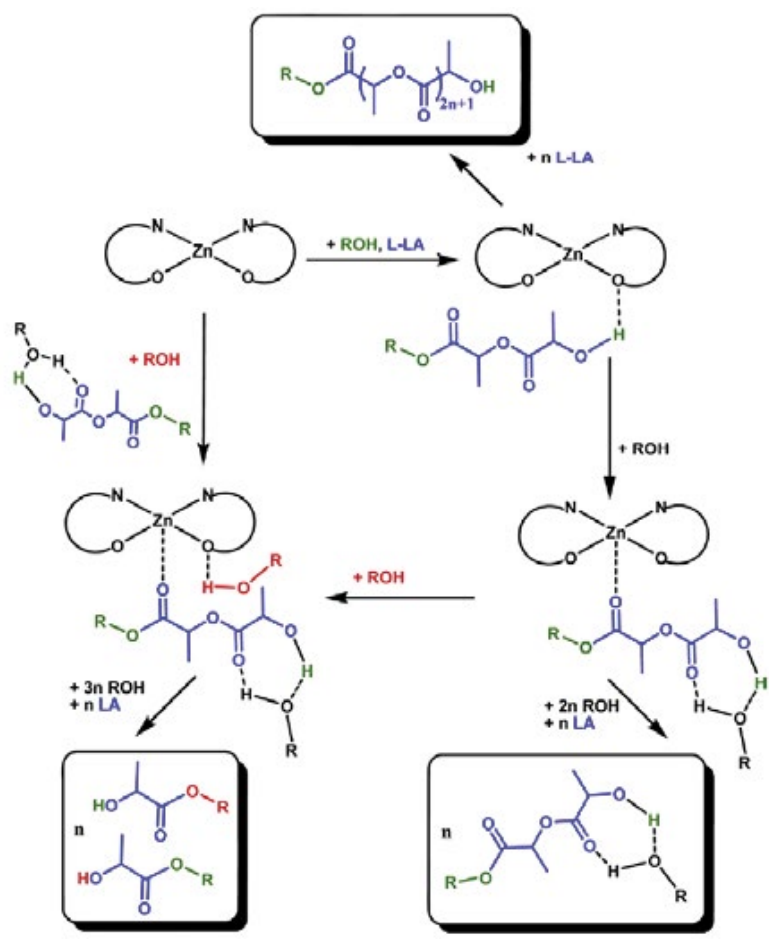

Figure 3: Proposed Mechanism for alcoholysis and ROP of LA [43].

methods with organic catalysts that do not include metals to use PLA materials that will apply to biomedical area or microelectronics area [44-47].

$\mathrm{N}-$ Heterocyclic Carbenes (NHC) is used as a nucleophilic organic catalyst for various transformation reactions of organic matters, and an interesting compound that shows action as a very good ligand for transition metals [48] (Figure 4).

Coulembier et al. studied a reaction that uses triazole carbene in Figure 4 [48]. Having reaction velocity of the linear function to alcohol, carbene and monomer means that the stage of speed limit occurs after the zwitterionic intermediate $\mathrm{Z}$ is formed. Esterification of acyl imidazolium intermediate (process $C$ ) is the rate determining step, and concentration of carbene compound 1 is controlled by reversible formation of alkoxytriazol 2.

\section{Cationic Catalysts}

ROP of lactide can be synthesized by canalization of the strong organic acid. General cationic ring-opening reaction can utilize a strong organic acid such as super acid as a catalyst. The initial process is that the ring of the lactide activated by receiving acid proton is opened by the attack of alcohol carbonyl, and lactyl alcohol is made. Examples that trifluoromethanesulfonic acid (HOTf) and methyl trifluoromethanesulfonate (MeOTf) catalyzes ring-opening reactions of lactide or glycolide are well known $[49,50]$.

HOTf activates oxygen of lactide so that alcohol can do nucleophilic attack as seen in Figure 5, cuts acyl group and catalyzes ring-opening reaction [51].

\section{Stereo-controlled Polymerization}

Stereochemistry is one of the most important factors deciding physical and chemical properties of polymers. Many single site catalysts composed of various multivalent ligands were synthesized, and synthetic methods are known to synthesize PLA matters stereocontrolled from DL-lactide [52] (Figure 6).

In reaction of $\left[_{\mathrm{Me}} \mathrm{BDI} \mathrm{DIPP}_{\mathrm{D}} \mathrm{SnOMe}(\mathrm{R}\right.$ of the Figure) and $(\mathrm{S}, \mathrm{S})$ lactide, a monomer is strongly affected by the structural constraint condition formed by the electron pair of tin, when it approaches to react. In Figure 6, the monomer combines weakly in the direction of trans of nitrogen donor of BDI ligand. The monomer and alkoxide ligand first exchange their sites by rotation, and then progress to TS1, the first transition state [52].

\section{Conclusion}

As PLA is the best candidate polymer to replace the nonbiodegradable synthetic polymers based on crude, many studies on synthesis and mechanism have been conducted to increase optical or mechanical properties of this polymer. This research reviewed the synthetic methods of poly(lactic acid) such as oligomer polycondensation and ring-opening polymerization, and examined

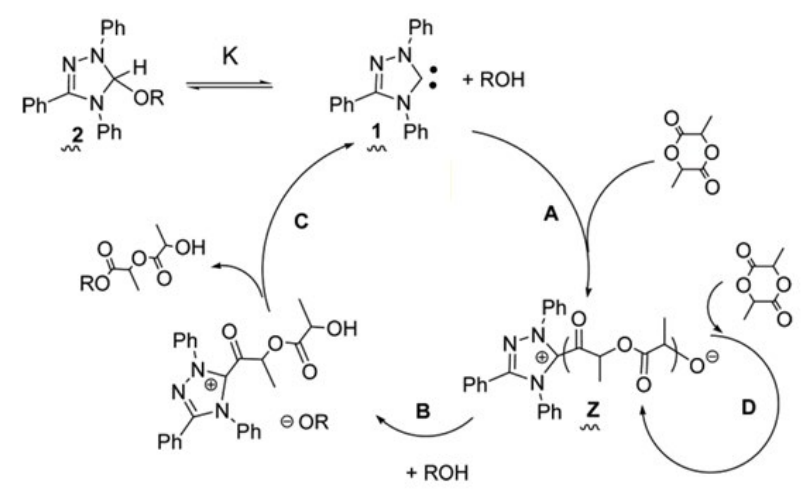

Figure 4: The Mechanism for the Polymerization of Lactide using Triazole Carbenes [48]

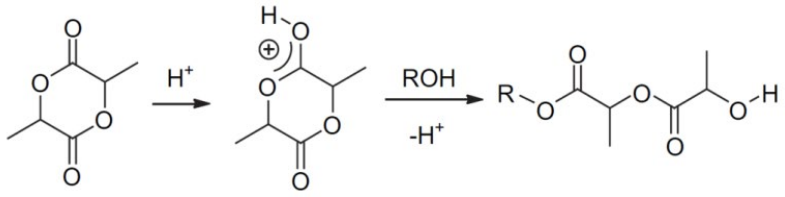

Figure 5: Proposed activated monomer pathway for the cationic ROP of lactide $(\mathrm{ROH}=$ the initiating protic agent or the growing polymer chain) [51]. 
Citation: Lee C, Hong S (2014) An Overview of the Synthesis and Synthetic Mechanism of Poly (Lactic acid). Mod Chem appl 2: 144. doi: 10.4172/2329-6798.1000144

Page 4 of 5

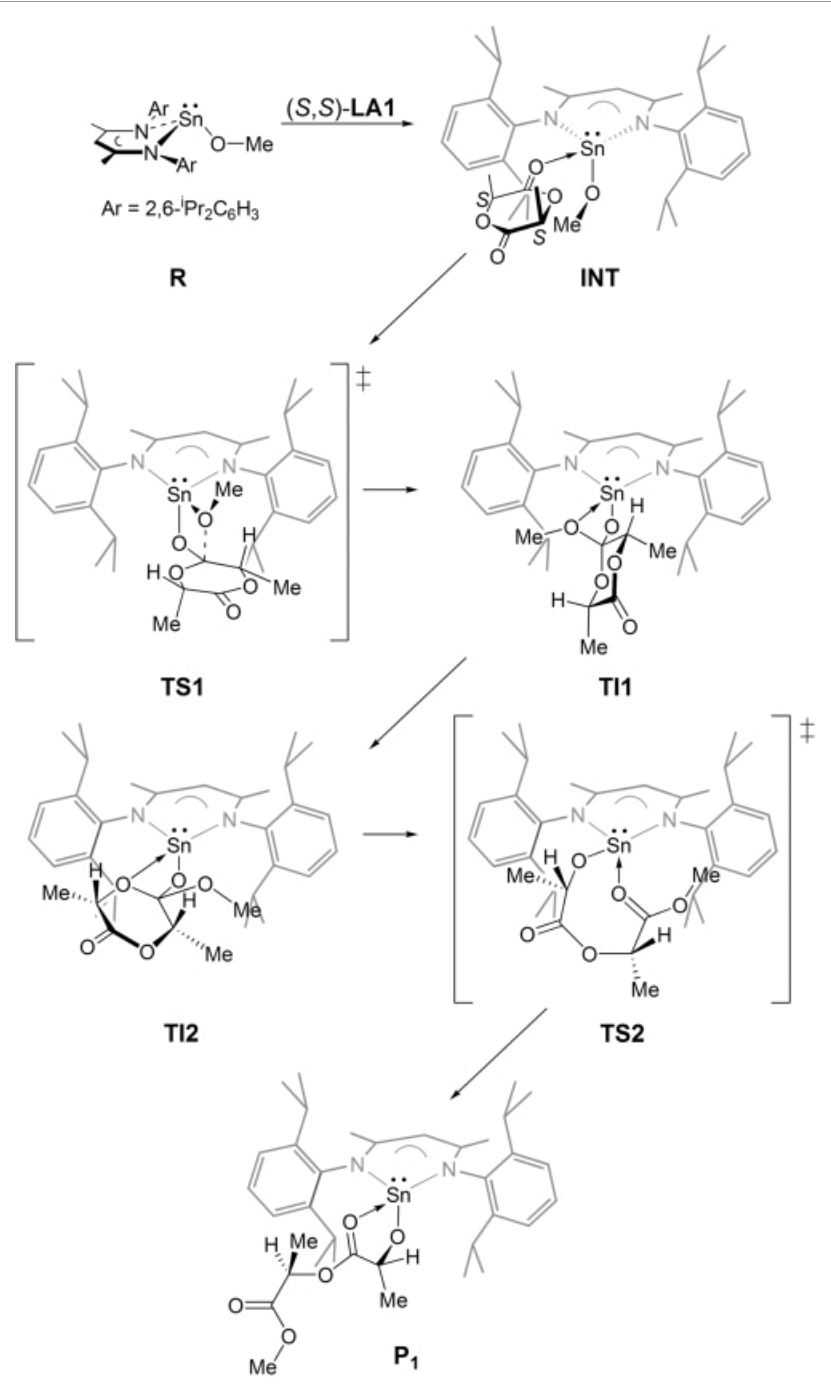

Figure 6: The proposed mechanism for the reaction between [MeBDIDIPP] SnOMe and (S,S)-lactide [52].

ring-opening reactions by classification of metal catalyst, organic catalyst, cationic catalyst and stereo-controlled polymerization.

\section{Acknowledgement}

This research was supported by Seokyeong University in 2013.

\section{References}

1. Avérous $L$ (2004) Biodegradable multiphase systems based on plasticized starch: A review. J Macromol Sci C 44: 231-274.

2. Yang KK, Wang $X L$, Wang $Y Z$ (2007) Progress in nanocomposite of biodegradable polymer. J Ind Eng Chem 13: 485-500.

3. Zhao H, Cui Z, Sun X, Turng LS, Peng X (2013) Morphology and Properties of Injection Molded Solid and Microcellular Polylactic Acid/PolyhydroxybutyrateValerate (PLA/PHBV) Blends. Ind Eng Chem Res 52: 2569-2581.

4. Bertrand A, Hillmyer MA (2013) Nanoporous poly(lactide) by olefin metathesis degradation. J Am Chem Soc 135: 10918-10921.

5. Inkinen S1, Hakkarainen M, Albertsson AC, Södergård A (2011) From lactic acid to poly(lactic acid) (PLA): characterization and analysis of PLA and its precursors. Biomacromolecules 12: 523-532.

6. Raquez JM, Barone DT, Luklinska Z, Persenaire O, Belayew A, et al. (2011) Osteoconductive and Bioresorbable Composites Based on Poly(L,L-lactide) and Pseudowollastonite: From Synthesis and Interfacial Compatibilization to In Vitro Bioactivity and In Vivo Osseointegration Studies. Biomacromolecules 12: $692-700$.
7. Vermonden T, Censi R, Hennink WE (2012) Hydrogels for protein delivery. Chem Rev 112: 2853-2888.

8. Danhier F, Ansorena E, Silva JM, Coco R, Le Breton A, et al. (2012) PLGAbased nanoparticles: an overview of biomedical applications. J Control Release 161: 505-522.

9. Lasprilla AJ, Martinez GA, Lunelli BH, Jardini AL, Filho RM (2012) Poly-lactic acid synthesis for application in biomedical devices - a review. Biotechnol Adv 30: 321-328.

10. Gupta B, Revagade N, Hilborn J (2007) J. Poly(lactic acid) fiber: an overview. Prog Polym Sci 34: 455-482.

11. Varadarajan S, Miller DJ (1999) Catalytic Upgrading of Fermentation-Derived Organic Acids. Biotechnol Prog 15: 845-854

12. Garlotta D (2001) A literature review of poly(lactic acid). Journal of Polymers and the Environment 9: 63-84.

13. Griffith LG (2000) Polymeric biomaterials. Acta Mater 48: 263-277.

14. Lim LT, Auras R, Rubino M (2008) Processing technologies for poly(lactic acid). Prog Polym Sci 33: 820-852.

15. Madhavan Nampoothiri K, Nair NR, John RP (2010) An overview of the recent developments in polylactide (PLA) research. Bioresour Technol 101: 84938501.

16. Södergard A, Stolt M (2002) Properties of lactic acid based polymers and their correlation with composition. Pro Polym Sci 27: 1123-1163.

17. Auras R, Harte B, Selke S (2004) An overview of polylactides as packaging materials. Macromol Biosci 4: 835-864.

18. Inkinen S, Hakkarainen M, Albertsson AC, Södergård A (2011) From lactic acid to poly(lactic acid) (PLA): characterization and analysis of PLA and its precursors. Biomacromolecules 12: 523-532.

19. Mehta R, Kumar V, Bhunia H, Upadhyay S (2005) Synthesis of poly(lactic acid): a review. Journal of Macromolecular Science, Part C: Polymer Reviews 45 325-349.

20. Dutkiewicz S, Grochowska-Lapienis D, Tomaszewski W (2003) Synthesis of poly $(\mathrm{L}(+)$ lactic acid) by polycondensation method in solution. Fibres Text Eastern Eur 11: 66-70.

21. Zhang W, Wang $Y(2008)$ Synthesis and properties of high molecular weigh poly(lactic acid) and its resultant fibers. Chinese J Polym Sci 26: 425-432

22. Lunt $J(1998)$ Large-scale production, properties and commercial applications of polylactic acid polymers. Polymer Degradation and Stability 59: 145-152.

23. Wang ZY, Zhao YM, Wang F, Wang J (2006) Syntheses of poly(lactic acidco-glycolic acid) serial biodegradable polymer materials via direct melt polycondensation and their characterization. J Appl Polym Sci 99: 244-252.

24. Moon S, Taniguchi I, Miyamoto M, Kimura Y, Lee CW (2001) Synthesis and Properties of High-Molecular-Weight Poly(L-lactic acid) by Melt/Solid Polycondensation under Different Reaction Conditions. High Perform Polym 13: S189-S196.

25. Lei ZQ, Bai YB, Wang SF (2005) Synthesis of high molecular weight polylactic acid from aqueous lactic acid co-catalyzed by tin(II)chloride dihydrate and succinic anhydride. Chinese Sci Bull 50: 2390-2392.

26. Gao Q, Lan P, Shao H, Hu X (2002) Direct synthesis with melt polycondensation and microstructure analysis of poly(L-lactic acid-co-glycolic acid). Polymer Journal 34: 786-793

27. Maharana T, Mohanty B, Negi YS (2009) Melt-solid polycondensation of lactic acid and its biodegradability. Progress in Polymer Science 34: 99-124

28. Gu SY, Yang M, Yu T, Ren TB, Ren J (2008) Synthesis and characterization of biodegradable lactic acid-based polymers by chain extension. Polym Int 57 982-986.

29. Ikeda K, Obuchi S, Ohta M (1995) Preparation process of polyhydroxycarboxylic acid. US Patent $5646238 \mathrm{~A}$.

30. Ichikawa F, Kobayashi M, Ohta M, Yoshida Y, Obuchi S, et al. (1995) Process for preparing polyhydroxycarboxylic acid. US Patent $5440008 \mathrm{~A}$.

31. Nikolic L1, Ristic I, Adnadjevic B, Nikolic V, Jovanovic J, et al. (2010) Nove microwave-assisted synthesis of poly(D,L-lactide): the influence of monomer initiator molar ratio on the product properties. Sensors (Basel) 10: 5063-5073. 
Citation: Lee C, Hong S (2014) An Overview of the Synthesis and Synthetic Mechanism of Poly (Lactic acid). Mod Chem appl 2: 144. doi: 10.4172/2329-6798.1000144

Page 5 of 5

32. Kim E, Shin EW, Yoo IK, Chung JS (2009) Characteristics of heterogeneous titanium alkoxide catalysts for ring-opening polymerization of lactide to produce polylactide. J Mol Catal A: Chem 298: 36-49

33. Köhn RD, Pan Z, Sun J, Liang C (2003) Ring-opening polymerization of,lactide with bis (trimethyl triazacyclohexane) praseodymium triflate. Catalysis Communications 4: 33-37.

34. Wu JC, Huang BH, Hsueh ML, Lai SL, Lin CC (2005) Ring-opening polymerization of lactide initiated by magnesium and zinc alkoxides. Polymer 46: $9784-9792$

35. Zhong Z, Schneiderbauer S, Dijkstra PJ, Westerhausen M, Feijen J (2003) Single-site calcium initiators for the controlled ring-opening polymerization of lactides and lactones. Polymer Bulletin 51: 175-182.

36. Sarazin Y, Schormann M, Bochmann M (2004) Novel zinc and magnesium alkyl and amido cations for ring-opening polymerization reactions. Organometallics 23: 3296-3302.

37. Chisholm MH, Lin CC, Galluccia JC, Ko BT (2003) Binolate complexes of lithium, zinc, aluminium, and titanium; preparations, structures, and studies of lactide polymerization. Dalton Trans 3: 406-412.

38. Nomura N, Ishii R, Akakura M, Aoi K (2002) Stereoselective ring-opening polymerization of racemic lactide using aluminum-achiral ligand complexes: exploration of a chain-end control mechanism. J Am Chem Soc 124: 59385939

39. Cheng Y, Deng S, Chen P, Ruan R (2009) Polylactic acid (PLA) synthesis and modifications: a review. Front Chem China 4: 259-264.

40. Ryner M, Stridsberg K, Albertsson AC, von Schenck $H$, Svensson $M$ (2001) Mechanism of Ring-Opening Polymerization of 1,5-Dioxepan-2one and L-Lactide with Stannous 2-Ethylhexanoate. A Theoretical Study, Macromolecules 34: 3877-3881.

41. Grijpma DW, Zondervan GJ, Pennings AJ (1991) High molecular weight copolymers of L-lactide and $\varepsilon$-caprolactone as biodegradable elastomeric implant materials. Polym Bull 25: 327-333.

42. Kricheldorf HR, Meier-Haack J (1993) Polylactones, 22 ABA triblock copolymers of L-lactide and poly(ethylene glycol). Makromol Chem 194: 715-725.
43. Jedrzkiewicz D, Czelusniak I, Wierzejewska M, Szafert S, Ejfler J (2015) Wellcontrolled, zinc-catalyzed synthesis of low molecular weight oligolactides by ring opening reaction Journal of Molecular Catalysis A: Chemical 396: 155-163.

44. Li H, Zhang S, Jiao J, Jiao Z, Kong L, et al. (2009) Controlled synthesis of polylactides using biogenic creatinine carboxylate initiators. Biomacromolecules 10: $1311-1314$.

45. Pang Z, Li H, He P, Wang Y, Ren H, et al. (2012) Controllable ring-opening copolymerization of L-lactide and (3S)-benzyloxymethyl-(6S)-methylmorpholine-2,5-dione initiated by a biogenic compound creatinine acetate. J. Polymer Sci Part A: Polymer Chemistry 50: 4004-4009.

46. Nyce GW, Csihony S, Waymouth RM, Hedrick JL (2004) A general and versatile approach to thermally generated $\mathrm{N}$-heterocyclic carbenes. Chemistry 10: $4073-4079$

47. Li H, Zhang S, Jiao J, Jiao Z, Kong L, et al. (2009) Controlled synthesis of polylactides using biogenic creatinine carboxylate initiators. Biomacromolecules 10: $1311-1314$

48. Coulembier O, Lohmeijer BGG, Dove AP, Pratt RC, Mespouille L, et al. (2006) Alcohol Adducts of N-Heterocyclic Carbenes: Latent Catalysts for the Thermally-Controlled Living Polymerization of Cyclic Esters. Macromolecules 39: 5617-5628.

49. Bourissou D, Moebs-Sanchez S, Martín-Vaca B (2007) Recent advances in the controlled preparation of poly( $\alpha$-hydroxy acids): Metal-free catalysts and new monomers. Comptes Rendus Chimie 10: 775-794.

50. Kricheldorf HR, Kreiser I (1987) Polylactones, 11. Cationic copolymerization of glycolide with L,L-dilactide. Makromol Chem 188: 1861-1873.

51. Penczek S (2000) Cationic ring-opening polymerization (CROP) majo mechanistic phenomena. J Polym Sci Part A: Polym Chem 38: 1919-1933.

52. Dove AP, Gibson VC, Marshall EL, Rzepa HS, White AJ, et al (2006) Synthetic structural, mechanistic, and computational studies on single-site betadiketiminate tin(II) initiators for the polymerization of rac-lactide. J Am Chem Soc 128: 9834-9843. 